\title{
El METABOLISMO ÁCIDO DE LAS CRASULÁCEAS: DIVERSIDAD, FISIOLOGÍA AMBIENTAL Y PRODUCTIVIDAD
}

\author{
José Luis Andrade", Erick De la Barrera², Casandra Reyes-García', \\ M. Fernanda Ricalde ${ }^{1}$, Gustavo Vargas-Soto ${ }^{1}$ y J. Carlos Cervera ${ }^{1,3}$ \\ 'Unidad de Recursos Naturales, Centro de Investigación Científica de Yucatán, A.C., \\ Calle 43 No. 130. Colonia Chuburná de Hidalgo, C.P. 97200, Mérida, Yucatán, México. \\ ${ }^{2}$ Centro de Investigaciones en Ecosistemas, Universidad Nacional Autónoma de México, \\ Apartado Postal 27-3, Morelia, 58089, Michoacán, México. \\ ${ }^{3}$ Departamento de Ecología Tropical, Campus de Ciencias Biológicas y Agropecuarias, Universidad Autónoma de \\ Yucatán, carretera Mérida-Xmatkuil km 15.5, Mérida, Yucatán, México. \\ ${ }^{4}$ Autor para la correspondencia: Tel. 52 (999) 9428330 ext. 369; Fax: 52 (999) 9813900; correo-e: andrade@cicy.mx
}

\begin{abstract}
Resumen: México posee una gran diversidad de especies con el Metabolismo Ácido de las Crasuláceas (CAM). Las especies c o $n$ este metabolismo pueden crecer en sitios donde la disponibilidad de agua es infrecuente, como son las zonas áridas y semiáridas y las copas de los árboles, o como hidrofitas en sitios con poca disponibilidad de $\mathrm{CO}_{2}$. Esta revisión presenta aspectos metodológicos, evolutivos, ecológicos y fisiológicos de este tipo de fotosíntesis. Además, se presentan datos de estudios recientes relacionados con la influencia de las condiciones ambientales en el ciclo diario de la fotosíntesis CAM. Finalmente, se presenta una reflexión sobre la falta de estudios en la fisiología de plantas CAM en México a pesar de su enorme diversidad.
\end{abstract}

Palabras clave: epifitas, indicadores ambientales, índice de productividad ambiental, isótopos estables, microambientes, plasticidad fisiológica.

\begin{abstract}
Mexico possesses a great species diversity of Crassulacean Acid Metabolism (CAM) plants. These plants can grow in places where water is infrequent, such as arid and semi-arid zones, and tree canopies, or as aquatic plants in places with low $\mathrm{CO}_{2}$ availability. This review presents methodological, evolutionary, ecological, and physiological aspects on CAM plants. Also, it shows data from recent studies related to the environmental effect on changes in the photosynthesis CAM. Finally, we made a consideration about the lack of studies on the physiology of CAM plants in Mexico despite its enormous diversity.

Key words: environmental indicators, environmental productivity index, epiphytes, microenvironments, physiological plasticity, stable isotopes.
\end{abstract}

$\mathbf{E}^{1}$ metabolismo ácido de las crasuláceas (CAM, siglas del nombre en inglés) es un ejemplo de adaptación al estrés ambiental y se presenta en plantas de sitios con periodos de escasa disponibilidad de agua o de $\mathrm{CO}_{2}$. Este tipo de fotosíntesis es uno de los tres encontrados en los tejidos de las plantas vasculares para la asimilación de $\mathrm{CO}_{2}$ de la atmósfera (Taiz y Zeiger, 2002; Larcher, 2003). La fotosíntesis $C_{3}$ (ciclo $\mathrm{C}_{3}$ o de Calvin-Benson) se realiza en los cloroplastos de todas las plantas con el uso de la enzima ribulosa 1, 5difosfato carboxilasa (rubisco) como catalizador de la reac- ción del $\mathrm{CO}_{2}$ con la ribulosa 1, 5-difosfato, y se llama así porque se producen dos moléculas de tres carbonos. La fotosíntesis $\mathrm{C}_{4}$ se presenta en plantas con una anatomía foliar llamada 'Kranz', caracterizada por tener células del mesófilo que rodean a las células que envuelven al haz vascular, en un arreglo en forma de corona. En el citoplasma de las células del mesófilo el $\mathrm{CO}_{2}$ es ligado al aceptor fosfoenol piruvato (PEP, siglas en inglés) con el uso de la enzima fosfoenol piruvato carboxilasa (PEPC) y se producen compuestos de cuatro carbonos, los cuales son transporta- 
dos a los cloroplastos de las células que envuelven el haz vascular, donde se realiza el ciclo $\mathrm{C}_{3}$ (Taiz y Zeiger, 2002; Larcher, 2003).

A diferencia de la fotosíntesis $\mathrm{C}_{3}$ y $\mathrm{C}_{4}$, en la fotosíntesis CAM las plantas fijan el $\mathrm{CO}_{2}$ principalmente por la noche con el uso de la enzima PEPC, pero el producto de la reacción de cuatro carbonos se almacena en vacuolas; luego, durante el periodo de luz consecutivo se asimila el $\mathrm{CO}_{2}$ en los cloroplastos por el ciclo $\mathrm{C}_{3}$ (Taiz y Zeiger, 2002; Larcher, 2003). Aproximadamente 7\% de las plantas vasculares presentan la fotosíntesis CAM (que incluye plantas del desierto, plantas acuáticas y epifitas), un porcentaje mucho mayor que el de las plantas con la fotosíntesis $\mathrm{C}_{4}$ (aprox. 1\%; Nobel, 1991a; Winter y Smith, 1996).

La fotosíntesis CAM consiste en los siguientes pasos metabólicos (Winter y Smith, 1996):

- Por la noche: (1) Formación del aceptor primario del $\mathrm{CO}_{2}$, fosfoenol-piruvato (PEP) a partir de carbohidratos no estructurales en las células fotosintéticas; (2) fijación del $\mathrm{CO}_{2}$ por la enzima PEP carboxilasa (PEPC) en el citosol y síntesis del ácido málico; (3) almacenaje del ácido málico (como ión malato) en la vacuola central de las células fotosintéticas.

- Durante el día: (1) Liberación del malato de la vacuola hacia el citosol; (2) descarboxilación del malato en el citosol, liberación de $\mathrm{CO}_{2}$ y formación de compuestos de tres carbonos (piruvato o PEP); (3) asimilación del $\mathrm{CO}_{2}$ liberado en los cloroplastos por la enzima rubisco, seguida por el ciclo de Calvin-Benson y la regeneración de carbohidratos de almacén o gluconeogénesis.

Existen variaciones al esquema anterior en las plantas CAM, como diferentes descarboxilasas durante el día, la acumulación de ácido cítrico además de málico, o diferentes precursores de PEP (Winter y Smith, 1996). Sin embargo, es en la respuesta al ambiente donde CAM presenta una mayor variación en la amplitud de las diferentes fases de este metabolismo, lo que hace difícil elaborar una definición correcta de la fotosíntesis CAM (Holtum, 2002; Lüttge, 2004).

\section{Metodologías para detectar la fotosíntesis CAM}

Titulación del tejido macerado. La determinación de los cambios diarios en acidez tisular ha sido una medición confiable de la actividad CAM y se ha practicado desde mucho antes de que se hicieran mediciones de fijación de $\mathrm{CO}_{2}$. El incremento en la acidez tisular es proporcional a la concentración de ácido málico en las vacuolas de las células, ya que por cada molécula de $\mathrm{CO}_{2}$ fijada por una planta $\mathrm{CAM}$ se produce una molécula de ácido málico y dos iones de hidrógeno (Nobel, 1988). Para medir la actividad CAM se requiere hacer dos titulaciones del tejido, una al anochecer y otra al amanecer, con una solución alcalina de $\mathrm{KOH}$ o $\mathrm{NaOH}$ en concentraciones del 0.01-0.05 N (Osmond et al.,
1994). La acidificación se expresa como el incremento nocturno del ácido málico en unidades de equivalentes de acidez o concentraciones de iones hidrógeno $\left(\mathrm{H}^{+}\right)$por peso fresco, por área o por volumen de agua de los tejidos (Medina et al., 1989).

El pH del punto final de la titulación depende del pK del ácido involucrado (pK $=-\log [\mathrm{K}]$, donde $[\mathrm{K}]$ denota la concentración de una base requerida para disociar $50 \%$ del ácido; Nelson y Cox, 2000). Como el ácido málico tiene un $\mathrm{pK}_{1}$ de 3.4 y un $\mathrm{pK}_{2}$ de 5.1 a $25^{\circ} \mathrm{C}$, la titulación a $\mathrm{pH} 6.5$ ó a 7 remueve $99 \%$ del $\mathrm{H}^{+}$que puede disociarse (Nobel, 1988; Osmond et. al., 1994). Para las especies que también acumulan ácido cítrico (Lüttge, 2006), el cual tiene tres carboxilos, se necesitaría titular hasta un $\mathrm{pH}$ de 8.4 para remover la mayor parte de $\mathrm{H}^{+}$, ya que el $\mathrm{pK}_{3}$ del ácido cítrico es de 6.4 (Franco et al., 1990).

Cuando se recolectan muchas muestras y la titulación no se puede hacer inmediatamente se recomienda almacenar las muestras en etanol al $80 \%$, en hielo seco o en nitrógeno líquido. Si se almacenan en etanol al $80 \%$, las muestras deben ser hervidas para evaporar el etanol y posteriormente hervidas con agua para extraer el ácido málico; también las muestras congeladas deben ser hervidas con agua. En todo caso debe evitarse la evaporación total del agua y enfriar el extracto antes de la titulación (Osmond et al., 1994).

Análisis enzimático. El método enzimático más conveniente para determinar la concentración de malato es con la malato deshidrogenasa (Hohorst, 1965) y para determinar la concentración de citrato se usa la citrato liasa (Möllering, 1985). Por lo general, sólo se requiere de un gramo del tejido fresco para estas determinaciones (Osmond et al., 1994). Estos métodos son idóneos para la determinación de ácidos orgánicos, pero mucho más caros que la titulación del tejido macerado.

Medición de la asimilación de $\mathrm{CO}_{2}$. La mejor manera de conocer la asimilación real de $\mathrm{CO}_{2}$ de la atmósfera por las plantas es midiendo el intercambio de gases con un analizador de gases en el infrarrojo (Nobel, 1988). Además, porque tanto el $\mathrm{CO}_{2}$ como el vapor de agua absorben la radiación infrarroja, el analizador de gases puede medir la tasa de asimilación de $\mathrm{CO}_{2}$ y la tasa de transpiración de las plantas (Osmond et al., 1994).

La curva de asimilación de $\mathrm{CO}_{2}$ clásica de Osmond (1978) muestra cuatro fases en plantas bien irrigadas (figura 1). La fase I corresponde a la asimilación de $\mathrm{CO}_{2}$ y la formación de ácidos orgánicos por la noche. En la fase II, al inicio del periodo de luz, ocurre el cierre estomático, pero en algunas plantas se presenta un aumento en la conductancia estomática y en la asimilación de $\mathrm{CO}_{2}$, y se presume que están involucradas la PEPC y la rubisco. En la fase III los ácidos orgánicos son descarboxilados, se pre- 


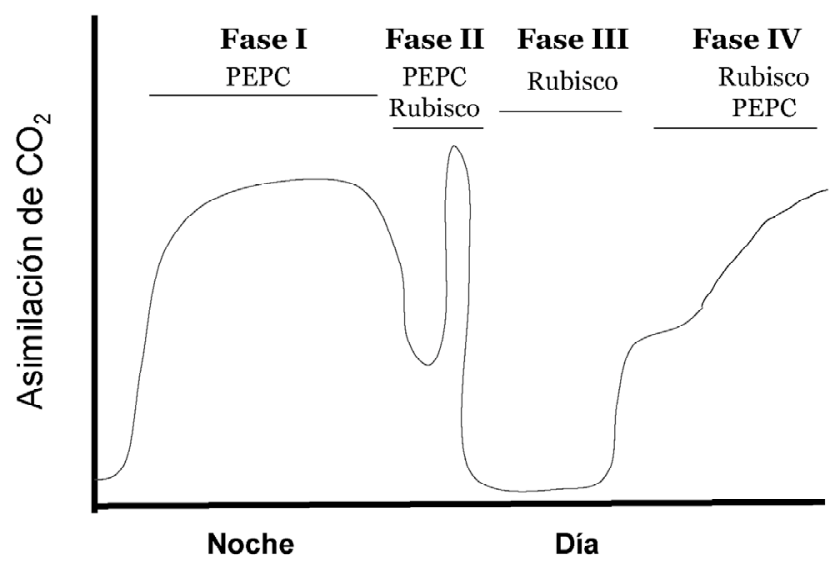

Figura 1. Curva de asimilación de $\mathrm{CO}_{2}$ de una planta CAM bien irrigada. Se muestran las cuatro fases típicas de la fotosíntesis CAM con las enzimas fijadoras de $\mathrm{CO}_{2}$ correspondientes.

senta la vía $\mathrm{C}_{3}$ y se acumulan los azúcares y el almidón. Cuando los ácidos orgánicos se agotan, los estomas se abren nuevamente y ocurre la fase IV, cuando el $\mathrm{CO}_{2}$ endógeno y exógeno es fijado por la rubisco y por la PEPC (Lambers et al., 1998). La figura 2 resume los patrones de intercambio de gases para una especie de agave y tres especies de las tres subfamilias de cactáceas (Nobel, 1988; Nobel y Bobich, 2002) y las variaciones en las cuatro fases.

Como la cámara que se usa en los analizadores de gases en el infrarrojo es diseñada para hojas delgadas, se requiere modificarla para poder medir las hojas suculentas o los tallos y frutos de las plantas CAM (Inglese et al., 1994; Nobel y De la Barrera, 2002). Además, como para obtener el intercambio de gases total en las cuatro fases de CAM se necesita medir por ciclos de 24 h, se pueden diseñar cámaras especiales para medir la asimilación total de una planta, lo cual es posible con plantas pequeñas, y obtener las mediciones automáticamente (Graham y Andrade, 2004; Cervera et al., 2007).

Isótopos estables del carbono. Otra herramienta importante de uso reciente para la evaluación de la plasticidad de las plantas CAM a los cambios ambientales es la técnica de isótopos estables del carbono $\left({ }^{12} \mathrm{C}\right.$ y $\left.{ }^{13} \mathrm{C}\right)$. La técnica se basa en que las enzimas carboxilantes (rubisco y PEPC) tienen diferente afinidad por los isótopos ${ }^{12} \mathrm{C}$ y ${ }^{13} \mathrm{C}$ del $\mathrm{CO}_{2}$. $\mathrm{La}$ enzima PEPC que fija el $\mathrm{CO}_{2}$ en la noche no discrimina y fija el $\mathrm{CO}_{2}$ con ambos isótopos, mientras que la rubisco fija el $\mathrm{CO}_{2}$ con el isótopo ${ }^{12} \mathrm{C}$ preferentemente (Goldstein et al., 1996; Squeo y Ehleringer, 2004; Santiago et al., 2005). El cociente ${ }^{13} \mathrm{C}$ sobre ${ }^{12} \mathrm{C}$ de la muestra con respecto al mismo cociente en un estándar (el índice ${ }^{13} \mathrm{C}$ o firma isotópica del carbono) se utiliza para diferenciar la vía principal de incorporación del carbono en las plantas (Santiago et al., 2005). Como las plantas CAM presentan fases en donde ambas enzimas, PEPC y rubisco, intervienen dentro del ciclo diurno de fijación de $\mathrm{CO}_{2}$, los valores de ${ }^{13} \mathrm{C}$ están entre los de las plantas $\mathrm{C}_{3}$ y $\mathrm{C}_{4}$ (Griffiths, 1988). También, las condiciones ambientales determinan en gran medida la contribución de la enzima carboxilante en la asimilación de $\mathrm{CO}_{2}$, puesto que las fases diurnas de asimilación de $\mathrm{CO}_{2}$ varían en función de la disponibilidad de agua, y cambios en la irradiación y la temperatura, entre otros factores (Nobel, 1988). De esta forma, es posible usar la firma isotópica del carbono como un indicador de estrés o del efecto de condiciones ambientales contrastantes dentro de una misma especie (Griffiths, 1988; Winter y Holtum, 2002; Holtum et al., 2004). Por esto, debe considerarse la contribución del $\mathrm{CO}_{2}$ respiratorio por la noche, así como la pérdida del $\mathrm{CO}_{2}$ fijado la noche anterior en la descarboxilación de la mañana siguiente (fase III de CAM), ya que la primera disminuye los valores de ${ }^{13} \mathrm{C}$ y la última los aumenta (Medina et al., 1989).

Una combinación de las técnicas de acidez tisular y de los isótopos estables del carbono ayudaría a detectar plantas con actividad CAM débil, las cuales tendrían un ${ }^{13} \mathrm{C}$

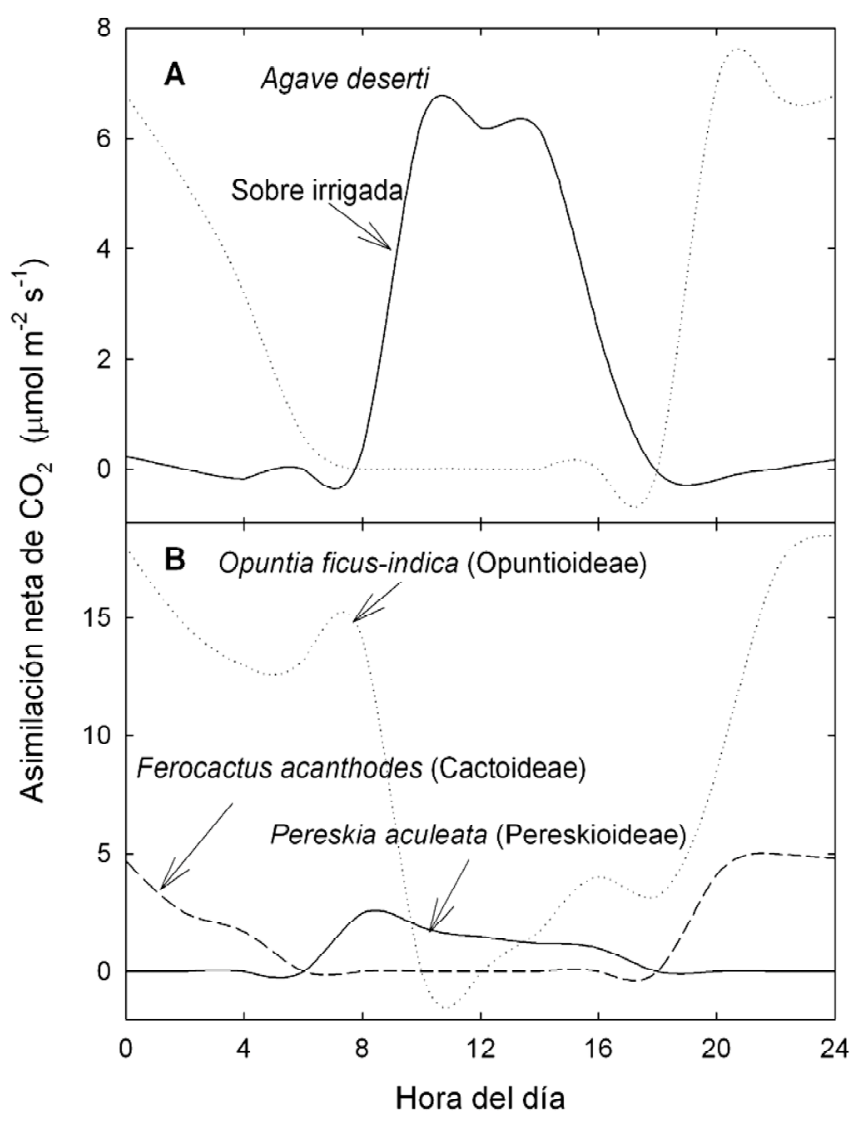

Figura 2. Patrones de intercambio de gases para (A) Agave deser ti (la línea de puntos muestra el intercambio gaseoso en condiciones óptimas) y (B) especies de cactáceas de diferentes subfamilias. Modificado de Nobel (1988) y Nobel y Bobbich (2002). 


\begin{tabular}{|c|c|c|c|}
\hline Era & Periodo & $\begin{array}{c}\text { Tiempo } \\
\text { (hace millones } \\
\text { de años) }\end{array}$ & \\
\hline \multirow{2}{*}{ 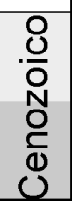 } & Cuaternario & 1.6 & $\begin{array}{l}\text { Dominan las angiospermas, } \\
\text { Disminuyen las concentraciones de } \mathrm{CO}_{2}\end{array}$ \\
\hline & Terciario & 66.4 & $\begin{array}{l}\text { Aparecen los primeros pastos, } \\
\text { Radiación de Bromeliaceae }\end{array}$ \\
\hline \multirow{3}{*}{ 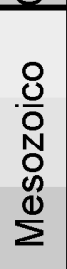 } & Cretácico & 144 & $\begin{array}{l}\text { Aparecen las angiospermas, } \\
\text { Cactaceae }\end{array}$ \\
\hline & Jurásico & 208 & $\begin{array}{l}\text { Dominan las gimnospermas } \\
\text { Plantas acuáticas }\end{array}$ \\
\hline & Triásico & 245 & $\begin{array}{l}\text { Se rompe la Pangea } \\
\text { Isoetes }\end{array}$ \\
\hline \multirow{5}{*}{ 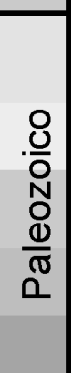 } & Pérmico & 286 & $\begin{array}{l}\text { Árboles y helechos, } \\
\text { Welwitschia (CAM 'cycling') }\end{array}$ \\
\hline & Carbonífero & 360 & Radiación de plantas vasculares e insectos \\
\hline & Devónico & 408 & Radiación de plantas terrestres $\quad \mathrm{O}_{2} \uparrow$ \\
\hline & Silúrico & 438 & Aparecen las primeras plantas vasculares \\
\hline & Ordovícico & 505 & Aparecen las primeras plantas terrestres \\
\hline
\end{tabular}

Figura 3. Evolución de las plantas en la escala geológica. Los eventos importantes en la evolución de CAM se resaltan en negritas y con subrayados.

típico de plantas $\mathrm{C}_{3}$ (Pierce et al., 2002; Zotz, 2002; Holtum et al., 2004; Silvera et al., 2005). No obstante, el trabajo reciente de Griffiths et al. (2007) comprueba, mediante mediciones simultáneas de intercambio de gases y de los isótopos estables ${ }^{13} \mathrm{C} \mathrm{y}{ }^{18} \mathrm{O}$ en las diferentes fases de CAM de Kalanchoe daigremontiana, que la discriminación al ${ }^{13} \mathrm{C}$ en realidad aumenta en la fase I (cuando actúa la PEPC) y disminuye en la fase IV (cuando actúan ambas enzimas carboxilantes). Esto haría que los valores de ${ }^{13} \mathrm{C}$ no reflejen exactamente la actividad CAM como ocurre en plantas $\mathrm{C}_{4}$, pero habría que comprobarlo con estudios en más especies.

\section{La evolución del CAM}

La vía fotosintética $\mathrm{C}_{3}$ surgió tempranamente en la escala geológica y todas las plantas vasculares actuales descienden de una planta con este tipo fotosintético (Gil, 1986; Griffiths, 1989; Raven y Spicer, 1996; Sage, 2002; Keeley y Rundel, 2003; Giordano et al., 2005). Hace más de 420 millones de años, el cociente $\mathrm{CO}_{2} / \mathrm{O}_{2}$ en la atmósfera era mucho mayor que en el presente (Raven y Spicer, 1996), y este cociente disminuyó al aumentar el número de organismos fotosintéticos que liberan $\mathrm{O}_{2}$ a la atmósfera, lo que provocó la ineficiencia actual de la enzima rubisco. Esta enzima es poco eficiente en la carboxilación porque además de fijar $\mathrm{CO}_{2}$, cataliza una reacción de oxigenación en el ciclo de la fotorespiración que no produce azúcares y utiliza energía (Ogren, 1984; Tolbert, 1997; Loomis y Amthor, 1999; Hausler et al., 2002; Lüttge, 2002). Ambas reacciones compiten entre sí, por lo que el aumento en fotorespiración disminuye la eficiencia de la fotosíntesis, especialmente a temperaturas atmosféricas elevadas. La conservación de la fotorespiración en la evolución de las plantas puede derivar de dos razones. La primera es que la complejidad de las reacciones fotosintéticas hace difícil conservar una mutación en la enzima central (rubisco) que no derive en desventaja adaptativa (Keeley y Rundel, 2003). La segunda es que la fotorespiración cumpla una función en la fotosíntesis, como puede ser la disipación de un exceso de electrones que evita la fotoinhibición (Gil, 1986; Streb et al., 2005).

Las fotosíntesis $\mathrm{C}_{4}$ y la CAM son los mecanismos que han surgido en la evolución de las plantas para disminuir la pérdida de energía asociada a la fotorespiración (Griffiths, 1989; Leegood, 2002; Lüttge, 2002; Keeley y Rundel, 2003; Giordano et al., 2005). Ambos tipos de fotosíntesis utilizan la PEPC para fijar el $\mathrm{CO}_{2}$, pero además esta enzima se encuentra en todas las células vegetales realizando funciones relacionadas con la síntesis de aminoácidos y regulación del pH (Hausler et al., 2002; Nimmo, 2003). En particular, las células estomáticas tienen una alta concentración de PEPC y vacuolas de gran tamaño (otra de las características comunes en plantas CAM), por lo que se ha 
planteado que la evolución del CAM surge cuando los caracteres expresados en los estomas se presentan en las células del mesófilo (Cockburn, 1981, 1985). De esta manera, el desarrollo de la fotosíntesis CAM no involucra la creación de nuevos genes, sino modificaciones en la regulación de los genes existentes (Griffiths et al., 2002; Nimmo, 2003).

La fotosíntesis CAM ha surgido de manera independiente en varias familias y existe una gran plasticidad en la expresión de este metabolismo (Dodd et al., 2002; Holtum, 2002). Se cree además que las primeras plantas CAM reutilizaban el carbono de la respiración (Gil, 1986; Griffiths, 1989; Griffiths et al., 1989; Raven y Spicer, 1996; Keeley y Rundel, 2003). A partir de éstas evolucionaron especies que requerían de manera más estricta del uso de carbono fijado durante la noche y se suprimió completamente la toma de carbono durante el día. Como la fotosíntesis CAM es costosa e implica limitaciones en la toma de carbono, por lo general las plantas CAM ocupan ambientes desfavo rables para el crecimiento de las plantas con fotosíntesis $\mathrm{C}_{3}$.

En la actualidad dos grupos contrastantes de plantas vasculares presentan metabolismo ácido en igual proporción (Keeley, 1998): las xerofitas y las hidrofitas. Ambos grupos parecen converger en el mismo tipo de metabolismo en respuesta a presiones de selección muy diferentes (Keeley y Rundel, 2003). El primer grupo responde a la capacidad de incrementar la eficiencia en el uso del agua al abrir los esto- mas en la noche cuando las tasas de transpiración son menores (Griffiths, 1989). Por otro lado, las hidrofitas habitan medios donde los organismos eutróficos disminuyen la concentración de $\mathrm{CO}_{2}$ del agua durante el día, por lo que la fijación nocturna confiere una ventaja evolutiva (Raven y Spicer, 1996; Keeley, 1998).

Se cree que versiones primitivas de la fotosíntesis CAM se presentaban ya en eucariontes acuáticos del Paleozoico, como una respuesta a la poca disponibilidad de $\mathrm{CO}_{2}$ diurna en lagos someros (Keeley y Rundel, 2003). En las plantas vasculares acuáticas, los primeros representantes CAM son miembros de la familia Isoetaceae que surgieron hace unos 230 millones de años (figura 3; Retallack, 1997). Entre las plantas terrestres, Welwitschia mirabilis, una gimnosperma que aparece desde el Pérmico (286 millones de años), presenta un metabolismo CAM rudimentario, tipo CAM de reciclaje (CAM 'cycling'), con actividad $\mathrm{C}_{3}$ y fijación nocturna de $\mathrm{CO}_{2}$ proveniente de la respiración (Ting y Burk, 1983; von Willert et al., 2005). Dado que las plantas terrestres CAM habitan lugares cálidos y secos que no promueven la formación de fósiles, poco se sabe de su radiación; sin embargo, es muy posible que haya ido acompañada de la radiación de las familias Cactaceae (en América), Didieraceae (en Madagascar) y Portulacaceae (en África) durante el Cretácico, ya que en éstas predomina la fotosíntesis CAM (Gibson y Nobel, 1986; Raven y Spicer, 1996). Un estudio realizado en la familia Bromeliaceae muestra

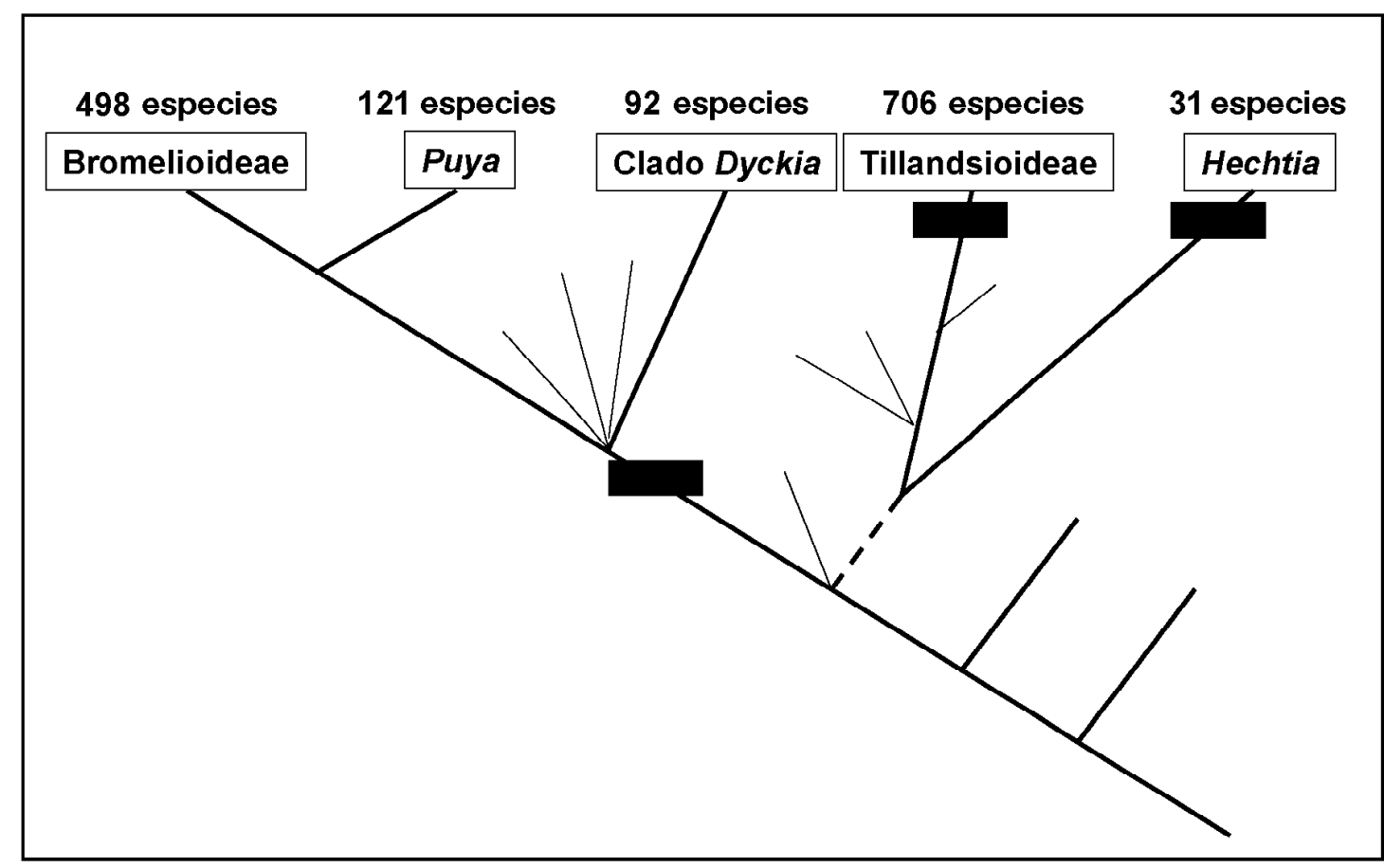

Figura 4. Filogenia y abundancia de especies $\mathrm{CAM}$ y $\mathrm{C}_{3}$ en la familia Bromeliaceae. Los cuadros negros marcan la aparición de CAM. El número de especies es el total de $\mathrm{C}_{3}$ y CAM, pero todas son CAM para el clado de Dyckia y para las especies de Hechtia (modificado de Crayn et al., 2004). 
que la fotosíntesis CAM se originó de manera independiente en tres ocasiones (figura 4) y que se perdió al menos en una ocasión (Crayn et al., 2004).

\section{Epifitas con CAM: el mayor grupo de plantas CAM}

Las epifitas viven en condiciones del dosel muy variables, principalmente en relación con la disponibilidad de agua. Por esto, éstas poseen adaptaciones para hacer frente a las condiciones secas: suculencia, cutículas impermeables, tricomas foliares, hojas en forma de roseta para retener y colectar el agua, y la fotosíntesis CAM (Lüttge, 1989; Benzing, 1990; Zotz y Andrade, 2002; Andrade et al., 2004). Se ha estimado que $57 \%$ de todas las epifitas son CAM (Lüttge, 2004) y que son más abundantes que las epifitas $\mathrm{C}_{3}$ en los sitios más expuestos del dosel y en los bosques más secos (Griffiths y Smith, 1983; Smith et al., 1986; Andrade et al., 2004).

Con cálculos conservadores, comprobamos que las especies CAM epifitas son realmente más numerosas que las especies CAM terrestres (figura 5). En estos cálculos hemos considerado que solamente la mitad de las orquídeas epifitas pudieran ser CAM y no las proporciones mayores a 50\% propuestas por Winter y Smith (1996) y Lüttge (2004). Por otro lado, estudios recientes sugieren que las especies CAM pueden ser aun mucho más numerosas de lo que se pensaba, sobre todo las especies de epifitas y hemiepifitas (Pierce et al., 2002; Silvera et al., 2005). No obstante, la proporción de epifitas CAM en muchos bosques tropicales no es buen indicador de la importancia de CAM en términos de individuos o biomasa, pues muchas especies CAM suelen ser orquídeas pequeñas y raras (Zotz, 2004).

La distribución de epifitas en el hospedero (forofito) no es aleatoria, pues se ha demostrado que en general se encuentran en sitios intermedios de los forofitos (Johansson, 1974; Graham y Andrade, 2004; Cervantes et al., 2005). De hecho, muchas epifitas y hemiepifitas CAM crecen mejor bajo sombra y un exceso de radiación puede reducir notablemente su fotosíntesis (Winter et al., 1983; Nobel y Hartsock, 1990; Raveh et al., 1995; Andrade y Nobel, 1996; Nobel y De la Barrera, 2004; Andrade et al., 2006). Las epifitas CAM pueden localizarse en los sitios más expuestos en varios bosques (Griffiths y Smith, 1983; Andrade y Nobel, 1997; Andrade et al., 2004), pero no necesariamente crecen mejor en esos sitios (Cervantes et al., 2005). Las epifitas CAM que crecen en sitios más expuestos deben ser además capaces de tolerar y disipar el exceso de energía luminosa (Griffiths y Maxwell, 1999; Andrade et al., 2004; Graham y Andrade, 2004).

Las epifitas obtienen el agua directamente de la lluvia o por escurrimientos del tronco y las ramas. Otras fuentes de agua, como el rocío y la niebla, pueden ser muy importantes para las bromeliáceas epifitas que absorben el agua por las hojas (Benzing, 1990; Andrade, 2003; Graham y
Andrade, 2004; Reyes-García et al., 2008). Además, las bromeliáceas epifitas CAM disminuyen su potencial hídrico foliar por la acumulación nocturna de ácidos, lo que incrementa su capacidad de absorber el rocío matinal (Smith et al., 1986; Griffiths, 1988; Andrade, 2003).

\section{Plasticidad fisiológica en plantas CAM}

Muchas plantas CAM han sido caracterizadas como facultativas o intermedias $\mathrm{C}_{3}-\mathrm{CAM}$, pues tienen la habilidad de expresar fotosíntesis $\mathrm{C}_{3}$ en respuesta a la disponibilidad de agua, a cambios en la humedad relativa, la temperatura del aire, en la cantidad y calidad de la luz, así como en el fotoperiodo (Lee y Griffiths, 1987; Borland y Griffiths 1992). Estas plantas se caracterizan por fijar $\mathrm{CO}_{2}$ durante el día (mediante rubisco) y durante la noche (mediante PEPC), con modificación en las fases II y III del modelo CAM (figura 1). La transición de $\mathrm{C}_{3}$ a CAM es benéfica para las plantas cuando se encuentran bajo estrés hídrico y altas temperaturas, porque el cierre diurno de los estomas evita la pérdida de agua y protege la integridad del aparato fotosintético (Winter y Ziegler, 1992). En el caso contrario, cuando existe disponibilidad de agua, las plantas que pasan de fotosíntesis CAM a fotosíntesis $\mathrm{C}_{3}$ pueden abrir los estomas durante el día, lo que garantiza una mayor fijación de $\mathrm{CO}_{2}$ (Andrade et al., en prensa).

Las especies $\mathrm{C}_{3}$-CAM se encuentran distribuidas en las Aizoaceae, Crassulaceae, Portulaceae, Vitaceae, Bromeliaceae y Clusiaceae (Smith y Winter, 1996). Entre las más representativas o conocidas se encuentran Sedum telephium L., que tiene una transición de $\mathrm{C}_{3}-\mathrm{CAM}$ por la falta de agua y una alta intensidad de luz (Borland y

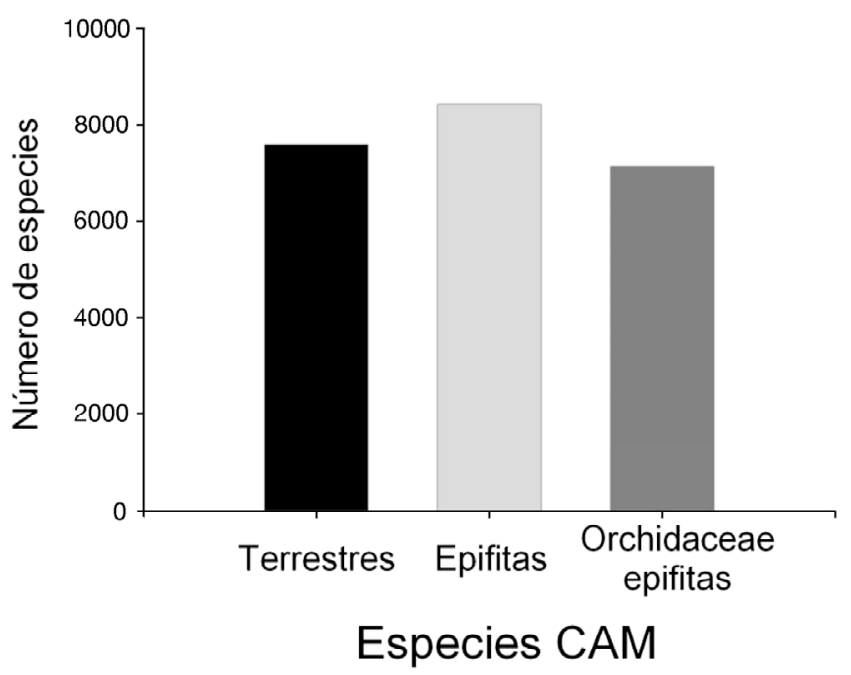

Figura 5. Número estimado de especies CAM terrestres y epifitas. Se incluye el número probable de especies de orquídeas epifitas CAM. Realizada con base en datos de Benzing (1990), Winter y Smith (1996) y Lüttge (2004). 
Griffiths 1992), y Mesembryanthemum crystallinum, a la cual se puede inducir la transición de $\mathrm{C}_{3}$ a CAM por la escasez de agua, la presencia de salinidad y una alta intensidad de luz, en un proceso gradual e irreversible (Keiller et al., 1994; Miszalski et al., 2001). Pero en otras especies, como las bromeliáceas, la inducción del $\mathrm{C}_{3}$ a CAM es más rápida y es reversible. Por ejemplo, la epifita Tillandsia usneoides puede fijar $\mathrm{CO}_{2}$ por un periodo de $24 \mathrm{~h}$ cuando crece en luz constante (Dodd et al., 2002). También, las epifitas $T$. brachycaulos y $T$. elongat a bien irri gadas pueden expresar fotosíntesis $\mathrm{C}_{3}$ y CAM, pero son totalmente CAM al restringirles el agua (Graham y Andrade, 2004; cuadro 1).

Un modelo particular es el de algunas especies del género Clusia (Clusiaceae), el cual incluye especies con individuos que pueden ser epifitas, hemiepifitas, arbustos y árboles (una excepción dentro de la fotosíntesis CAM), y que además presenta una alta plasticidad en la expresión de la fotosíntesis CAM como respuesta a los cambios ambientales (Lüttge, 2006). Es en este género donde se expresan al menos cuatro tipos fotosintéticos. (1) La fotosíntesis $\mathrm{C}_{3}$. (2) La fotosíntesis CAM 'fuerte' (Holtum et al., 2004) con asimilación de $\mathrm{CO}_{2}$ nocturna y algo de asimilación diurna y las típicas cuatro fases señaladas en el modelo de Osmond (1978). En este grupo se encuentra la variante llamada CAM reducida (CAM 'idling'), donde los estomas se cierran completamente cuando la sequía es severa y el $\mathrm{CO}_{2}$ respiratorio es re-fijado en la noche y reciclado a carbohidratos durante el día (Lüttge, 2006). (3) La fotosíntesis $\mathrm{C}_{3}$ $\mathrm{CAM}$, que puede variar entre puramente la vía $\mathrm{C}_{3}$, la intermedia $\mathrm{C}_{3}-\mathrm{CAM}$ y la CAM. Finalmente, (4) la fotosíntesis CAM de reciclaje (CAM 'cycling') donde durante el día ocurre la vía $\mathrm{C}_{3}$ y en la noche, con los estomas cerrados, el $\mathrm{CO}_{2}$ respiratorio es fijado por la PEPC y los ácidos orgánicos producidos son descarboxilados durante el día. Las especies en este grupo pueden tener fluctuaciones de ácidos del tipo CAM 'fuerte' o CAM 'débil' (Guralnick y Jackson, 2001; Holtum et al., 2004).

Entonces, podemos observar que existe un continuo de plantas que van desde $\mathrm{C}_{3}$ hasta CAM 'fuerte' y nos enfrentamos a la tarea de entender la importancia ecológica de esta plasticidad fisiológica intra- e interespecífica (Holtum, 2002; Zotz, 2002). Si a estas observaciones le sumamos el hecho de que la mayor diversidad de especies CAM está en los trópicos, la tarea de los investigadores se hace colosal por la multiplicidad de microambientes producto de la estacionalidad en las lluvias, la estructura vertical de los bosques, la fenología de los árboles y por la gran variedad de formas de crecimiento.

Por último, debemos discutir el descubrimiento de especies $\mathrm{C}_{4}$ que pueden cambiar a CAM en algunos miembros del género Portulaca (Sayed, 1998; Lara et al., 2003), cuya actividad enzimática y regulación son modificadas por la sequía. Sin embargo, las fotosíntesis $\mathrm{C}_{4}$ y CAM son incom- patibles dentro de un mismo tejido vegetal porque en la fotosíntesis $\mathrm{C}_{4}$ la anatomía foliar separa espacialmente la vía $\mathrm{C}_{3}$ de la $\mathrm{C}_{4}$, mientras que en la fotosíntesis CAM la separación de ambas vías es temporal. Cuando ambos tipos de fotosíntesis se presentan en una misma especie operan en células u órganos diferentes (Guralnick et al., 2002; Sage, 2002).

\section{Microambientes y plantas CAM}

Las especies CAM más suculentas y con mayor capacidad de almacenamiento de agua pueden mantener por más tiempo la tasa máxima de asimilación de $\mathrm{CO}_{2}$ y un balance positivo de carbono, aun después de 30 días de sequía (Nobel, 1988). Por otro lado, la asimilación neta de $\mathrm{CO}_{2}$ depende también de la cantidad de radiación que llega a las plantas. Para cactáceas que crecen expuestas en ambientes áridos, la asimilación de $\mathrm{CO}_{2}$ tiende a incrementarse de manera lineal con el flujo de fotones para la fotosíntesis (FFF, longitudes de onda entre 400 y $700 \mathrm{~nm}$ ) y se satura cuando el flujo de fotones para la fotosíntesis (FFF) total diaria alcanza $30 \mathrm{~mol} \mathrm{~m}^{-2} \mathrm{~d}^{-1}$ (Nobel, 1988). En contraste, para Hylocereus undatus, una cactácea hemiepifita que crece en sitios sombreados en ambientes tropicales, un FFF por encima de $20 \mathrm{~mol} \mathrm{~m}^{-2} \mathrm{~d}^{-1}$ conduce a la reducción en la asimilación de $\mathrm{CO}_{2}$ (Nobel y De la Barrera, 2004; Andrade et al., 2006). Asimismo, una combinación de baja humedad relativa en el aire y alta radiación induce fotoinhibición en

Cuadro 1. Algunos ejemplos de plantas $\mathrm{C}_{3}-\mathrm{CAM}$ y el factor que induce los cambios de $\mathrm{C}_{3}$ a CAM o de $\mathrm{C}_{3}$ a $\mathrm{C}_{3}$-CAM.

\begin{tabular}{|c|c|c|c|}
\hline Especie & Familia & $\begin{array}{l}\text { Factor } \\
\text { inductor }\end{array}$ & Referencia \\
\hline $\begin{array}{l}\text { Mesembryanthemum } \\
\text { crystallinum }\end{array}$ & Aizoaceae & $\begin{array}{l}\text { Luz, agua } \\
\text { o salinidad }\end{array}$ & $\begin{array}{l}\text { Keiller et al. } \\
\text { (1994) }\end{array}$ \\
\hline Sedum telephium & Crassulaceae & Agua y luz & $\begin{array}{l}\text { Borland y } \\
\text { Griffiths } \\
(1992)\end{array}$ \\
\hline $\begin{array}{l}\text { Tillandsia } \\
\text { brachycaulos y } \\
\text { T. elongata }\end{array}$ & Bromeliaceae & Agua & $\begin{array}{l}\text { Graham y } \\
\text { Andrade } \\
(2004)\end{array}$ \\
\hline Clusia minor & Clusiaceae & $\begin{array}{l}\text { Agua, luz, } \\
\text { temperatura, } \\
\text { humedad } \\
\text { relativa }\end{array}$ & $\begin{array}{l}\text { Borland et al. } \\
\text { (1998) }\end{array}$ \\
\hline C. rosea & Clusiaceae & $\begin{array}{l}\text { Agua, luz, } \\
\text { temperatura y } \\
\text { humedad } \\
\text { relativa }\end{array}$ & $\begin{array}{l}\text { Borland et al. } \\
\text { (1998) }\end{array}$ \\
\hline C. parviflora & Clusiaceae & Agua y luz & $\begin{array}{l}\text { Herzog et al. } \\
\text { (1999) }\end{array}$ \\
\hline
\end{tabular}


ciertas especies CAM (figura 6), donde la eficiencia cuántica máxima no se recupera durante la noche (Cervantes $e t$ al., 2005).

Existe una relación directa entre la radiación que llega a las plantas y el régimen térmico en el que crecen. Para plantas CAM de sitios tropicales, la tasa de asimilación de $\mathrm{CO}_{2}$ es máxima cuando la temperatura diurna/nocturna es similar a la temperatura anual media de las regiones donde son nativas (Nobel, 1988). Así, para Agave fourcroydes (Nobel, 1985) e Hylocereus undatus (Nobel y De la Barrera, 2002), dos especies que coexisten en la selva baja caducifolia de Yucatán, la temperatura diurna/nocturna óptima para la asimilación de carbono es $30 / 20^{\circ} \mathrm{C}$. En comparación, la temperatura diurna/nocturna óptima para la asimilación de $\mathrm{CO}_{2}$ en Agave desert $i$ y Ferocactus acantho des, especies del desierto, es $25 / 15^{\circ} \mathrm{C}$ (Nobel, 1988). Los regímenes térmicos por debajo o por encima del óptimo se traducen en la reducción de la tasa de asimilación de $\mathrm{CO}_{2}$. La mayor temperatura nocturna óptima para la asimilación de $\mathrm{CO}_{2}$ en especies CAM tropicales, en comparación con la menor temperatura nocturna óptima de especies CAM del desierto, refleja la plasticidad de CAM (Nobel, 1988; Cervera et al., 2006; Andrade et al., 2008). Además, una dificultad en la disipación del exceso de calor de las hojas en epifitas CAM (figura 7) puede reducir el crecimiento e incluso impedir la reproducción de los individuos en ciertos microambientes (Cervantes et al., 2005).

Los estudios sobre las respuestas fisiológicas de las plantas CAM al ambiente han sido realizados principalmente en miembros adultos de sólo tres familias: A gavaceae, Bromeliaceae y Cactaceae (Nobel, 1988; Benzing, 1990; Winter y Smith, 1996; Zotz y Hietz, 2001; Andrade et al., 2004; Lüttge, 2004; Andrade et al., 2008) y la mayoría son estudios a corto plazo con plantas de zonas áridas. Es necesario poner mayor atención en la fisiología ambiental de muchas otras especies CAM desde la germinación, hasta la vía fotosintética de las plántulas y la supervivencia de los individuos en diferentes microambientes (Schmidt et al., 2001; Zotz y Hietz, 2001; Andrade et al., 2004; Ayala-Cordero et al., 2006; Cervera et al., 2006; Méndez et al., 2006; Hernández-González y BrionesVillareal, 2007).

El enfoque microambiental también ayuda a entender varios aspectos ecológicos en las plantas CAM. Muchas especies con este tipo de fotosíntesis crecen y se reproducen más en ciertos microambientes que les permiten obtener más agua y luz adecuada (Graham y Andrade, 2004; Cervantes et al., 2005). Por ejemplo, para la cactácea amenazada Mammillaria gaumeri, los individuos que crecen entre $40-80 \%$ del FFF diario total tienen mayores tasas de crecimiento que los que crecen a mayores o menores cantidades de radiación (figura 8; Cervera et al., 2007). En todo caso, los individuos que crecen en sitios menos favorables (mayor que $80 \%$ o menor que $40 \%$ del FFF total diario)

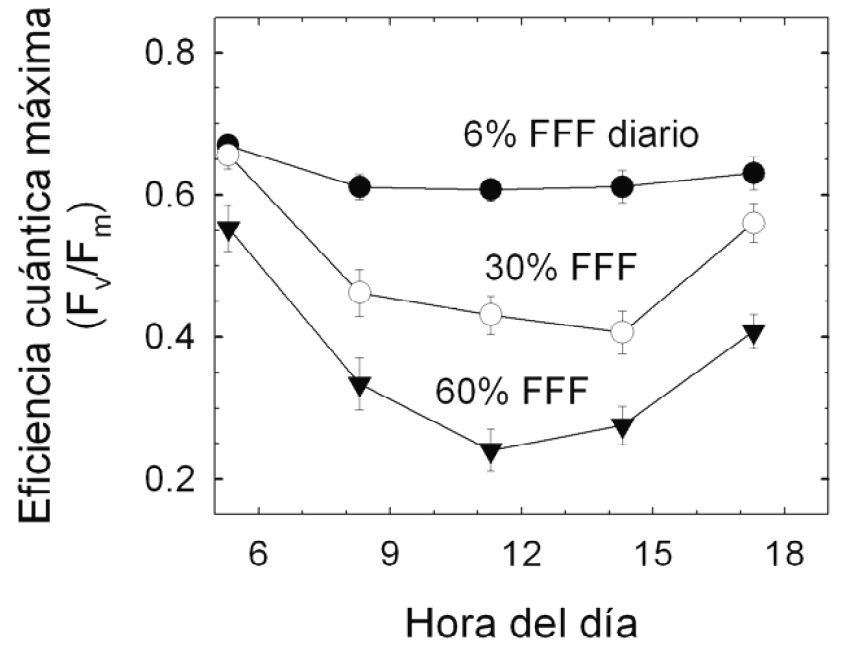

Figura 6. Curso diario de la eficiencia cuántica máxima $\left(\mathrm{F}_{\mathrm{v}} / \mathrm{Fm}_{\mathrm{m}}\right)$ para Tillandsia brachycaulos durante la estación seca en Mérida, Yucatán, México. Los individuos fueron aclimatados a tres regímenes de flujo de fotones para la fotosíntesis (FFF) con respecto al total diario un mes antes de las mediciones. Los datos son promedios \pm error estándar (modificado de Cervantes et al., 2005).

ganan menos carbono por tener una menor tasa de fotosíntesis o mayores tasas respiratorias, y al invertir los productos de la fotosíntesis para obtener agua y reparar los centros de reacción tendrían menos defensas contra patógenos y depredadores. De esta manera, los estudios demográficos deberían tomar en cuenta el microambiente dentro de su matriz de datos, ya que el crecimiento poblacional puede ser sostenido principalmente por los individuos que crecen en ciertos microhábitats.

\section{Índice de productividad ambiental}

Algunas de las especies vegetales más productivas son pastos cultivados como el trigo y el maíz, lo cual es el resultado de la selección artificial y del mejoramiento de las condiciones ambientales al proporcionar riego y fertilizantes. Al considerar que las plantas CAM frecuentemente se encuentran en zonas áridas y semiáridas o, como las epifitas, en microambientes limitados por una baja disponibilidad de agua o temperaturas extremas, se podría pensar que su productividad es sustancialmente baja. Sin embargo, debido a que estas plantas fijan $\mathrm{CO}_{2}$ durante la noche y algunas especies también lo hacen durante el día, cuando las condiciones ambientales son buenas, su productividad neta por día o por cosecha puede ser comparable a las de especies agrícolas $\mathrm{C}_{3}$ y $\mathrm{C}_{4}$ (Nobel, 2005). Específicamente, algunas plantas CAM cultivadas pueden alcanzar productividades de $47 \mathrm{Mg} \mathrm{ha}^{-1} \mathrm{año}^{-1}$, mientras que las $\mathrm{C}_{3}$ pueden alcanzar $39 \mathrm{Mg} \mathrm{ha}^{-1}$ año ${ }^{-1}$ y las $\mathrm{C}_{4} 49 \mathrm{Mg} \mathrm{ha}^{-1}$ año ${ }^{-1}$ (cuadro 2; Nobel, 1991a). 


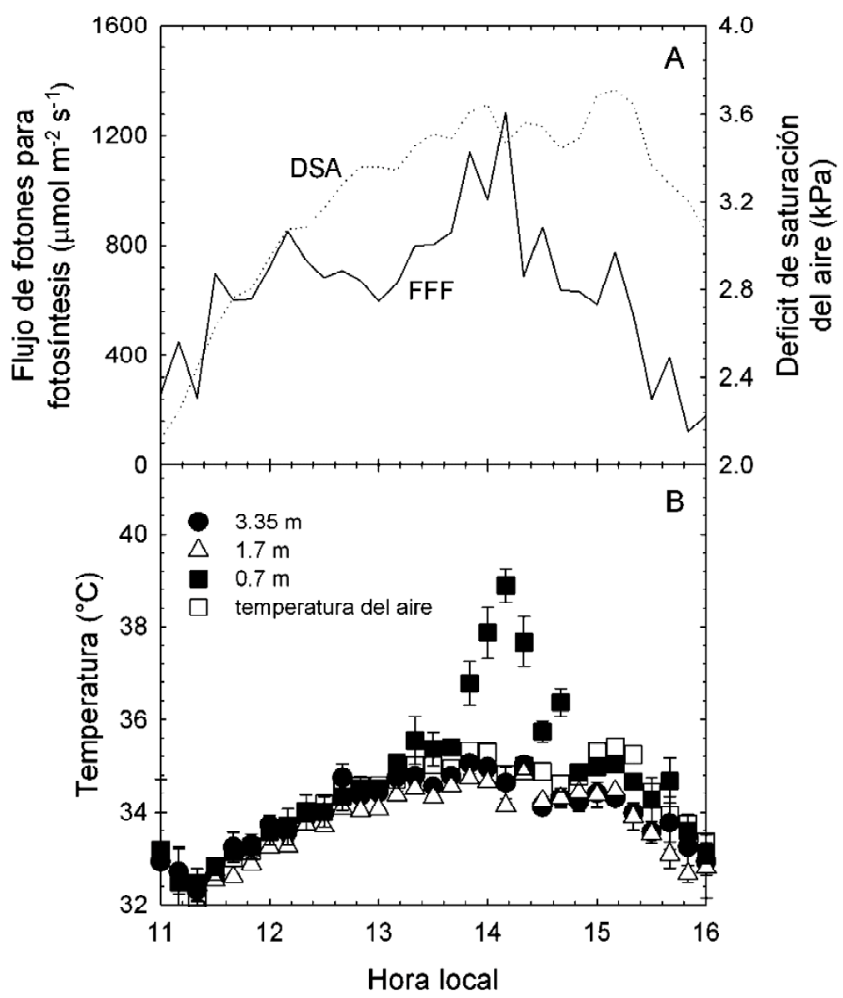

Figura 7. Curso diario de (A) flujo de fotones para la fotosíntesis (FFF), déficit de saturación del aire (DSA) y (B) temperaturas de las hojas de Tillandsia brachycaulos y del aire en un bosque seco de Yucatán, México. Los datos de temperatura foliar son promedios \pm error estándar de individuos creciendo en las tres alturas en un árbol (modificado de Cervantes et al., 2005).

La productividad de plantas CAM se puede predecir mediante el llamado Índice de Productividad Ambiental (IPA) a partir de las respuestas fisiológicas de individuos bajo condiciones controladas en el laboratorio (Nobel, 1984, 1988, 1991a; De la Barrera y Andrade, 2005; cuadro 3). En particular, se considera la respuesta de la asimilación neta de $\mathrm{CO}_{2}$ bajo distintos niveles del flujo de fotones para la fotosíntesis (FFF), el potencial hídrico del suelo y la temperatura del aire. Mientras dos de los factores mencionados se mantienen fijos, el tercero es manipulado progresivamente y después de un periodo de aclimatación se mide la respuesta de la planta. Así, se pueden crear índices de FFF, agua y temperatura, cuyos valores oscilan entre 1, cuando la condición ambiental es la óptima y la asimilación neta de $\mathrm{CO}_{2}$ es máxima, y 0 , cuando la condición ambiental detiene la asimilación de $\mathrm{CO}_{2}$. En algunos casos, el IPA será negativo, cuando el factor en estudio provoque una respiración celular mayor que la asimilación fotosintética de $\mathrm{CO}_{2}$, por lo que la asimilación neta sería menor que cero.

$\mathrm{Si}$ se presupone que los factores ambientales considerados son independientes, el IPA = Índice de FFF Índice de Agua Índice de Temperatura. De esta manera, si las con- diciones de dos factores ambientales son las óptimas para la asimilación de $\mathrm{CO}_{2}$, pero el tercer factor presenta condiciones limitantes, el valor del IPA se verá reducido. A la fecha se han generado IPAs para alrededor de 20 especies de agaváceas y cactáceas (ver ejemplos en cuadro 3 y Nobel, 1988). En algunos casos, la diferencia entre la productividad calculada y la medida en el campo es menor que 1\% (Nobel, 1988, 1991a). Además de proporcionar información sobre la ecofisiología de especies vegetales en el campo, los IPAs son modelos numéricos que pueden utilizarse como herramientas de predicción con aplicaciones en agricultura y conservación. Por ejemplo, en Chile se ha utilizado el enfoque del IPA para establecer plantaciones comerciales de nopal (Opuntia ficus-indica) altamente productivas (García de Cortázar et al., 1985; García de Cortázar y Nobel, 1992). También se han utilizado los IPA en combinación con datos climatológicos para determinar zonas adecuadas para el cultivo de Agave tequilana en Jalisco (Pimienta-Barrios et al., 1999) y de Hylocereus undatus y Opuntia ficus-indica en California, E.E.U.U. (Nobel et al., 2002). Recientemente se obtuvo un IPA para Mammillaria gaumeri, cactácea endémica y amenazada de la costa norte de Yucatán, con el fin de identificar sitios adecuados para su reintroducción y poder crear condiciones ambientales adecuadas para su propagación en el invernadero (J.C. Cervera y J.L. Andrade, datos no publicados).

\section{Plantas CAM como indicadores del cambio global}

Hay evidencias de que las plantas que coexisten en ambientes donde el agua es limitante responden a los patrones estacionales de precipitación (Schwinning et al., 2003;

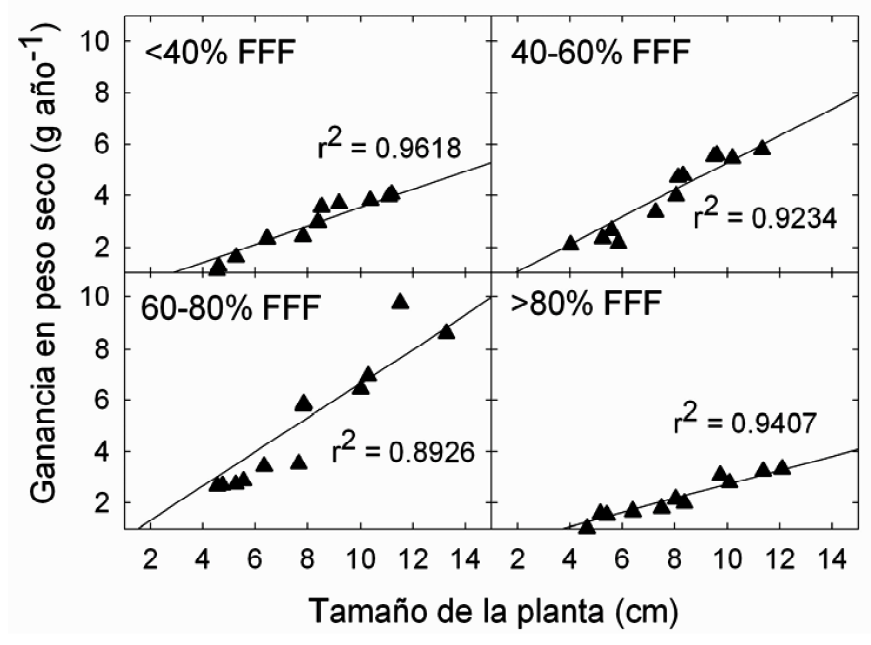

Figura 8. Ganancia anual en peso seco de individuos de diferentes tamaños de Mammillaria gaumeri que crecen en cuatro regímenes del flujo de fotones para la fotosíntesis (FFF) en dos ecosistemas de Yucatán, México (modificado de Cervera et al., 2007). 
Cuadro 2. Productividades máximas alcanzadas por algunas especies cultivadas. Datos tomados de Nobel (1991a) con permiso de The New Phytologist Trust.

\begin{tabular}{|c|c|c|}
\hline Especie & Fotosíntesis & $\begin{array}{l}\text { Productividad } \\
\left(\mathrm{Mg} \mathrm{ha}^{-1} \text { año }^{-1}\right)\end{array}$ \\
\hline Agave mapisaga & CAM & 38 \\
\hline A. salmiana & CAM & 42 \\
\hline Ananas comosus & CAM & 35 \\
\hline Beta vulgaris & $\mathrm{C}_{3}$ & $30-34$ \\
\hline Cynodon dactylon & $\mathrm{C}_{4}$ & 32 \\
\hline Eucalyptus globulus & $\mathrm{C}_{3}$ & 40 \\
\hline Lolium perenne & $\mathrm{C}_{3}$ & 29 \\
\hline Medicago sativa & $\mathrm{C}_{3}$ & $30-34$ \\
\hline Opuntia amyclaea & CAM & 45 \\
\hline O. ficus-indica & CAM & 47 \\
\hline Pinus radiata & $\mathrm{C}_{3}$ & $34-38$ \\
\hline Saccharum officinarum & $\mathrm{C}_{4}$ & $50-67$ \\
\hline Salix purpurea & $\mathrm{C}_{3}$ & 36 \\
\hline Sorghum bicolor & $\mathrm{C}_{4}$ & 47 \\
\hline Triticum aestivum & $\mathrm{C}_{3}$ & 30 \\
\hline Zea mays & $\mathrm{C}_{4}$ & $26-40$ \\
\hline
\end{tabular}

Reynolds et al., 2004; Schwinning y Sala, 2004; Schwinning et al., 2004; Sher et al., 2004). Por otro lado, con el actual calentamiento climático global se predice que habrá cambios en el patrón de lluvias, con sequías más largas y cambios en la proporción de años secos y lluviosos (Villers-Ruiz y Trejo-Vázquez, 1997; Easterling et al., 2000; Groisman et al., 2004; Groisman et al., 2005). Estos cambios podrían afectar a las poblaciones de plantas CAM, especialmente a las epifitas porque no tienen acceso al agua que se acumula en el suelo.

Muchos estudios con especies de la familia Bromeliaceae describen los patrones de distribución de las especies epifitas en los estratos del dosel, o en diversos ambientes, siguiendo un gradiente de precipitación, temperatura y radiación solar, así como la relación entre su distribución y fisiología (Pittendrigh, 1948; Griffiths et al., 1986; Griffiths y Maxwell, 1999; Andrade, 2003; Graham y Andrade, 2004; Cervantes et al., 2005; Reyes-García, 2005). También está documentada la disminución poblacional de la especie Tillandsia brachycaulos durante un año seco, en comparación con los años lluviosos en el mismo ambiente (Mondragón et al., 2004). Estos estudios apuntan a que las bromeliáceas epifitas podrían ser un indicador de los cambios en el clima, pues sus especies tienen menos elementos para sobreponerse al cambio en el patrón de lluvias y otros factores ambientales que los forofitos. De hecho, estas plantas podrían ser un indicador más sensible de lo que a más largo plazo podría observarse con otras especies y que pocos trabajos han logrado documentar, por falta de bases de datos de largo plazo para reportar estos cambios (Tamis et al., 2005). Aunado a esto está el hecho de que bromeliáceas epifitas con fotosíntesis CAM pueden ser marcadores de la señal isotópica del vapor de agua de la atmósfera, lo que abre nuevas posibilidades de investigación y de uso de estas plantas como indicadoras ambientales (Reyes-García, 2005; Helliker y Griffiths, 2007; ReyesGarcía y Andrade, 2007).

\section{Perspectivas}

México posee quizás la mayor diversidad de plantas CAM del mundo y esto se debe a que es el centro de diversificación de las cactáceas y las agaváceas, cuyos miembros son mayoritariamente CAM (Hernández y Godínez-Álvarez, 1994; García-Mendoza y Galván, 1995). De México se han exportado los mayores cultivos CAM de importancia mundial (Nobel, 1994): el nopal (Opuntia ficus-indica), el sisal (Agave sisalana) y más recientemente la pitahaya (Hylocereus undatus). De hecho, el nopal es la planta CAM más extensamente cultivada a nivel mundial, con un área de cultivo mayor [más de un millón de hectáreas $(40 \%$ en Brasil para forraje)] que la de otra planta CAM productiva, la piña (unas 300,000 ha), originaria de Sudamérica(Nobel, 2002). Por otra parte, México posee una gran cantidad de ecosistemas tropicales, desde las dunas costeras hasta los bosques de niebla, y el mayor número de especies CAM está en esos ecosistemas. No obstante, el mayor esfuerzo de investigación fisiológica ha sido destinado a especies desérticas y de cultivo (Nobel, 2002; Andrade et al., en prensa).

Entre los estudios de la respuesta fisiológica de plantas

Cuadro 3. Algunas especies CAM cuyos índices de productividad ambiental (IPA) han sido obtenidos.

\begin{tabular}{lll}
\hline Especie & Hábitat & Referencia \\
\hline Agave deserti & $\begin{array}{l}\text { Desiertos de } \\
\text { Estados Unidos }\end{array}$ & Nobel (1984) \\
Agave fourcroydes & Cultivado en Yucatán & Nobel (1985) \\
Agave lecheguilla & Desierto de Chihuahua & $\begin{array}{l}\text { Nobel y Quero } \\
(1986)\end{array}$ \\
Agave tequilana & Cultivado en Jalisco & $\begin{array}{l}\text { Nobel y } \\
\text { Valenzuela (1987) }\end{array}$ \\
Ferocactus acanthodes & $\begin{array}{l}\text { Desiertos de } \\
\text { Estados Unidos }\end{array}$ & $\begin{array}{l}\text { Nobel (1986) } \\
\text { Hylocereus undatus }\end{array}$ \\
$\begin{array}{l}\text { Cultivado } \\
\text { mundialmente }\end{array}$ & $\begin{array}{l}\text { Nobel et al. } \\
(2002)\end{array}$ \\
Opuntia ficus-indica & $\begin{array}{l}\text { Cultivado } \\
\text { mundialmente }\end{array}$ & Nobel (1991b) \\
\hline
\end{tabular}


CAM al ambiente existen pocos con especies tropicales en ambientes contrastantes a lo largo del año y bajo condiciones naturales (Zotz y Winter, 1994; Zotz y Andrade, 1998; Cervantes et al., 2005; Andrade et al., 2006; Cervera et al., 2006, 2007). Se requieren esfuerzos para la formación de recursos humanos para la investigación de este tipo de fotosíntesis en todos los ecosistemas de México y esperamos que esta revisión aliente a más estudiantes a integrarse a los diferentes equipos que trabajan con este tipo de plantas en nuestro país.

\section{Agradecimientos}

A Park S. Nobel, Howard Griffiths y Klaus Winter por las múltiples discusiones acerca de las plantas CAM en diversos ecosistemas. A Elizabeth Osorio por alentarnos a escribir esta revisión. A Luis Simá, Eric Graham, Sandra Cervantes, Roberth Us, Manuel Mandujano, Elizabeth Rengifo, Rafael Barceló, Manuel Cach, Olivia HernándezGonzález y Claudia González por su participación en nuestro laboratorio en diferentes tópicos de investigación de las plantas CAM. A la Dra. Mónica Mejía-Chang y un revisor anónimo por los atinados comentarios en una versión previa del manuscrito. CONACYT proporcionó becas doctorales a J.C. Cervera, G. Vargas-Soto y M.F. Ricalde y una beca posdoctoral a C. Reyes-García. E. De la Barrera realizó una estancia posdoctoral con apoyo de UC-MEXUS. Este trabajo fue parcialmente financiado por el Fondo Sectorial de Ciencia Básica SEP-Conacyt No. 48344/24588.

\section{Literatura citada}

Andrade J.L. 2003. Dew deposition on epiphytic bromeliad leaves: an important event in a Mexican tropical dry deciduous forest. Journal of Tropical Ecology 19:479-488.

Andrade J.L. y Nobel P.S. 1996. Habitat, $\mathrm{CO}_{2}$ uptake and growth for the CAM epiphytic cactus Epiphyllum phyllanthus in a Panamanian tropical forest. Journal of Tropical Ecology 12:291-306.

Andrade J.L. y Nobel P.S. 1997. Microhabitats and water relations of epiphytic cacti and ferns in a lowland neotropical forest. Biotropica 29:261-270.

Andrade J.L., Cervera J.C. y Graham E.A. En prensa. Microenvironments, water relations and productivity of CAM plants. En: De la Barrera E. y Smith W.K. Eds. Perspectives in Biophysical Plant Ecophysiology: a Tribute to Park S. Nobel, Mildred Mathias Botanical Garden, Los Angeles, CA.

Andrade J.L., Graham E.A. y Zotz G. 2004. Determinantes morfofisiológicos y ambientales de la distribución de epifitas en el dosel de bosques tropicales. En: Marino-Cabre ra H. Ed. Fisiología Ecológica en Plantas. Mecanismos y Respuestas a Estrés en Los Ecosistemas, pp. 139-156, Ediciones Universitarias de Valparaíso, Valparaíso, Chile.

Andrade J.L., Rengifo E., Ricalde M.F., Simá J.L., Cervera J.C. y Vargas-Soto G. 2006. Microambientes de luz, crecimiento y fotosíntesis de la pitahaya (Hylocereus undatus) en un agrosis- tema de Yucatán, México. Agrociencia 40:687-697.

Ayala-Cordero G., Terrazas T., López-Mata L. y Trejo C. 2006. Morpho-anatomical changes and photosynthetic metabolism of Stenocereus beneckei seedlings under soil water deficit. Journal of Experimental Botany 57:3165-3174.

Benzing D.H. 1990. Vascular Epiphytes. Cambridge University Press, Cambridge.

Borland A.M. y Griffiths H. 1992. Properties of phosphoenolpyruvate carboxilase and carbohydrate accumulation in the $\mathrm{C}_{3}$ CAM intermediate Sedum telephium L. Grown under different light and watering regimes. Journal of Experimental Botany 43:353-361.

Borland A.M., Tecsi L.I., Leegood R.C. y Walker R.P. 1998. Inducibility of crassulacean acid metabolism (CAM) in Clusia species: physiological/biochemical characterization and intercellular localization of carboxylation and decarboxylation processes in three species which exhibit different degrees of CAM. Planta 205:342-351.

Cervantes S.E., Graham E.A. y Andrade J.L. 2005. Light microhabitats, growth and photosynthesis of an epiphytic bromeliad in a tropical dry forest. Plant Ecology 179:107-118.

Cervera J.C., Andrade J.L., Simá J.L. y Graham E.A. 2006. Microhabitats, germination, and establishment for Mammillaria gaumeri (Cactaceae), a rare species from Yucatan. International Journal of Plant Sciences 167:311-319.

Cervera J.C., Andrade J.L., Graham E.A., Durán R., Jackson P.C. y Simá J.L. 2007. Photosynthesis and optimal light microhabitats for a rare cactus, Mammillaria gaumeri, in two tropical ecosystems. Biotropica 39:620-627.

Cockburn W. 1981. The evolutionary relationship between stomatal mechanism, crassulacean acid metabolism and $\mathrm{C}_{4}$ photosynthesis. Plant, Cell and Environment 4:417-418.

Cockburn W. 1985. Stomatal mechanism as the basis of evolution of crassulacean acid metabolism. Nature 314:200.

Crayn D.M., Winter K. y Smith J.A.C. 2004. Multiple origins of crassulacean acid metabolism and the epiphytic habit in the Neotropical family Bromeliaceae. Proceedings of the National Academy of Sciences of the United States of America 101:37033708.

De la Barrera E. y Andrade J.L. 2005. Challenges to plant megadiversity: how environmental physiology can help. New Phytologist 167:5-8.

Dodd A.N., Borland A.M., Haslam R.P., Griffiths H. y Maxwell K. 2002. Crassulacean acid metabolism: plastic, fantastic. Journal of Experimental Botany 53:569-580.

Easterling D.R., Meehl G.A., Parmesan C., Changnon S.A., Karl T.R. y Mearns L.O. 2000. Climate extremes: Observations, modeling, and impacts. Science 289:2068-2074.

Franco A.C., Ball E. y Lüttge U. 1990. Patterns of gas exchange and organic acid oscillations in tropical trees of the genus Clusia. Oecologia 85:108-114.

García de Cortázar V., Acevedo E. y Nobel P.S. 1985. Modeling of PAR interception and productivity by Opuntia ficus-indica. Agricultural and Forest Meteorology 34:145-162.

García de Cortázar V. y Nobel P.S. 1992. Biomass and fruit production for the prickly pear cactus, Opuntia ficus-indica. Journal of the American Society for Horticultural Sciences 117:558-562.

García-Mendoza A. y Galván V.R. 1995. Riqueza de las familias Agavaceae y Nolinaceae en México. Boletín de la Sociedad 
Botánica de México 56:7-24.

Gibson A.C. y Nobel P.S. 1986. The Cactus Primer. Harvard University Press, Londres.

Gil F. 1986. Origin of CAM as an alternative photosynthetic carbon fixation pathway. Photosynthetica 20:494-507.

Giordano M., Beardall J. y Raven J.A. 2005. $\mathrm{CO}_{2}$ concentrating mechanisms in algae: mechanisms, environmental modulation, and evolution. Annual Review of Plant Biology 56:99-131.

Goldstein G., Meinzer F., Sternberg L., Jackson P., Cavelier J. y Holbrook N. 1996. Evaluating aspects of water economy and photosynthetic performance with stable isotopes from water and organic matter. En: Mulkey S.S., Chazdon R.L. y Smith A.P. Eds. Tropical Forest Plant Ecophysiology, pp. 244-267, Chapman \& Hall, Nueva York.

Graham E.A. y Andrade J.L. 2004. Drought tolerance associated with vertical stratification of two co-occurring epiphytic bromeliads in a tropical dry forest. American Journal of Botany 91:699-706.

Griffiths H. 1988. Crassulacean acid metabolism: a re-appraisal of physiological plasticity in form and function. Advances in Botanical Research 15:43-92.

Griffiths H. 1989. Carbon dioxide concentrating mechanisms and the evolution of CAM in vascular epiphytes. En: Lüttge U. Ed. Vascular Plants as Epiphytes: Evolution and Ecophysiology, Springer, Nueva York.

Griffiths H., Cousins A.B., Badger M.R. y von Caemmerer S. 2007. Discrimination in the dark. Resolving the interplay between metabolic and physical constraints to phosphoenolpyruvate carboxylase activity during the crassulacean acid metabolism cycle. Plant Physiology 143:1055-1067.

Griffiths H., Helliker B., Roberts A., Haslam R.P., Girnus J., Robe W.E., Borland A.M. y Maxwell K. 2002. Regulation of rubisco activity in crassulacean acid metabolism plants: better late than never. Functional Plant Biology 29:689-696.

Griffiths H., Ong B.L., Avadhani P.N. y Goh C.J. 1989. Recycling of respiratory $\mathrm{CO}_{2}$ during crassulacean acid metabolism: Alleviation of photoinhibition in Pyrrosia piloselloides. Planta 179:115-122.

Griffiths H., Lüttge U., Stimmel K.H., Crook C.E., Griffiths N.M. y Smith J.A.C. 1986. Comparative ecophysiology of CAM and $\mathrm{C}_{3}$ bromeliads. III. Environmental influences on $\mathrm{CO}_{2}$ assimilation and transpiration. Plant Cell and Environment 9:385-393.

Griffiths H. y Maxwell K. 1999. In memory of C. S. Pittendrigh: Does exposure in forest canopy relate to photoprotective strategies in epiphytic bromeliads? Functional Ecology 13:15-23.

Griffiths H. y Smith J.A.C. 1983. Photosynthetic pathways in the Bromeliaceae of Trinidad: relations between life-forms, habitat preference and the occurrence of CAM. Oecologia 60:176-184.

Groisman P.Y., Knight R.W., Easterling D.R., Karl T.R., Hegerl G.C. y Razuvaev V.A.N. 2005. Trends in intense precipitation in the climate record. Journal of Climate 18:1326-1350.

Groisman P.Y., Knight R.W., Karl T.R., Easterling D.R., Sun B.M. y Lawrimore J.H. 2004. Contemporary changes of the hydrological cycle over the contiguous United States: Trends derived from in situ observations. Journal of Hydrometeorology 5:64-85.

Guralnick L.J., Edwards G., Ku M.S.B., Hockema B. y Franceschi V.R. 2002. Photosynthetical and anatomical characteristics in the $\mathrm{C}_{4}$-crassulacean acid metabolism-cycling plant, Portulaca grandiflora. Functional Plant Biology 29:763-773.

Guralnick L.J. y Jackson M.D. 2001. The occurrence and phylo- genetics of crassulacean acid metabolism in the Portulacaceae. International Journal of Plant Sciences 162:257-262.

Hausler R.E., Hirsch H.J., Kreuzaler F. y Peterhänsel C. 2002. Overexpression of $\mathrm{C}_{4}$-cycle-enzimes in transgenic $\mathrm{C}_{3}$ plants: a biotechnological approach to improve $\mathrm{C}_{3}$ photosynthesis. Journal of Experimental Botany 53:591-607.

Helliker B.R. y Griffiths H. 2007. Towards a plant-based proxy for the ${ }^{18} \mathrm{O}$ atmospheric water vapor. Global Change Biology 13:723-733.

Hernández-González O. y Briones-Villarreal O. 2007. Crassulacean acid metabolism photosynthesis in columnar cactus seedlings during ontogeny: the effect of light on nocturnal acidity accumulation and chlorophyll fluorescence. American Journal of Botany 94:1344-1351.

Hernández H.M. y Godinez-Álvarez H. 1994. Contribución al conocimiento de las cactáceas mexicanas amenazadas. Acta Botanica Mexicana 26:33-52.

Herzog B., Hubner C., Ball E., Bastos R.do.N., Franco A.C., Scarano F.R. y Lüttge U. 1999. Comparative study of the $\mathrm{C}_{3} / \mathrm{CAM}$ intermediate species Clusia parviflora (Saldanha) Engl. and the obligate CAM species Clusia hilariana Schltdl. growing sympatrically exposed and shaded in the coastal restinga of Brazil. Plant Biology 1:453-459.

Hohorst H.J. 1965. L(-)-malate, determination with malate dehydrogenase and DPN. En: Bergmeyer H.U. Ed. Methods of Enzimatic Analysis, pp. 328-334, Academic Press, Londres.

Holtum J.A.M. 2002. Crassulacean acid metabolism: plasticity in expression, complexity of control. Functional Plant Biology 29:657-661.

Holtum J.A.M., Aranda J., Virgo A., Gehring H.H. y Winter K. 2004. ${ }^{13} \mathrm{C}$ values and crassulacean acid metabolism in Clusia species from Panama. Trees 18:658-668.

Inglese P., Israel A.A. y Nobel P.S. 1994. Growth and $\mathrm{CO}_{2}$ uptake for cladodes and fruit of the Crassulacena acid metabolism species Opuntia ficus-indica during fruit develoment. Physiologia Plantarum 91:708-714.

Johansson D. 1974. Ecology of vascular epiphytes in West African rain forest. Acta Phytogeographica Suecica 59:1-136.

Keeley J.E. 1998. CAM photosynthesis in submerged aquatic plants. Botanical Review 64:121-175.

Keeley J.E. y Rundel P.W. 2003. Evolution of CAM and $\mathrm{C}_{4}$ carbon-concentrating mechanisms. International Journal of Plant Sciences 164:S55-S77.

Keiller D.R., Scolombe S.P. y Cockburn W. 1994. Analysis of chlorophyll a fluorescence in $\mathrm{C}_{3}$ and CAM forms of Mesembryanthemum crystallinum. Journal of Experimental Botany 45:325-334.

Lambers H., Chapin III F.S.y Pons T.L. 1998. Plant Physiological Ecology. Springer, Nueva York.

Lara M.V., Disante K.B., Podestá F.E., Andreo C.S. y Drincovich M.F. 2003. Induction of a Crassulacean acid like metabolism in the $\mathrm{C}_{4}$ succulent plant, Portulaca oleracea L.: physiological and morphological changes are accompanied by specific modifications in phosphoenolpyruvate carboxilase. Photosynthesis Research 77:241-254.

Larcher, W. 2003. Physiological Plant Ecology. Ecophysiology and Stress Physiology of Functional Groups. Springer, Berlín.

Lee H.S.J. y Griffiths H. 1987. Induction and repression of CAM in Sedum telephium L. in response to photoperiod and water stress. Journal of Experimental Botany 38:834-841. 
Leegood R.C. 2002. $\mathrm{C}_{4}$ photosynthesis: principles of $\mathrm{CO}_{2}$ concentration and prospects for its introduction into $\mathrm{C}_{3}$ plants. Journal of Experimental Botany 53:581-590.

Loomis R.S. y Amthor J.S. 1999. Yield potential, plant assimilatory capacity, and metabolic efficiencies. Crop Science 39:1584-1596.

Lüttge U. 1989. Vascular Plants as Epiphytes. Springer, Berlín.

Lüttge U. 2002. $\mathrm{CO}_{2}$ concentrating: consequences in crassulacean acid metabolism. Journal of Experimental Botany 53:21312142.

Lüttge U. 2004. Ecophysiology of crassulacean acid metabolism (CAM). Annals of Botany 93:629-652.

Lüttge U. 2006. Photosynthetic flexibility and ecophysiological plasticity: questions and lessons from Clusia, the only CAM tree, in the neotropics. New Phytologist 171:7-25.

Medina E., Olivares E., Díaz M. y Van der Merve N. 1989. Metabolismo ácido de crasuláceas en bosques húmedos tropicales. Monographs in Systematic Botany from the Missouri Botanical Garden 27:56-67.

Méndez M., Dorantes A., Dzib G., Argáez J. y Durán R. 2006. Germinación y establecimiento de plántulas de Pterocereus gaumeri, una cactácea columnar, rara y endémica de Yucatán, México. Boletín de la Sociedad Botánica de México 79:33-41.

Miszalski Z., Niewiadomska E., Slesak I., Lüttge U., Kluge M. y Ratajczak R. 2001. The effect of irradiance on carboxylating/decarboxylating enzymes and fumarase activities in Mesembryanthemum crystallinum L. exposed to salinity stress. Plant Biology 3:17-23.

Möllering H. 1985. Citrate. Determination with citrate ly ase, $\mathrm{MDH}$ and LDH. En: Bergmeier H.U. Ed. Methods of Enzymatic Analysis, pp. 2-12, Academic Press, San Diego.

Mondragón D., Durán R., Ramírz I. y Valverde T. 2004. Temporal variation in the demography of the clonal epiphyte Tillandsia brachycaulos (Bromeliaceae) in the Yucatan Peninsula, Mexico. Journal of Tropical Ecology 20:189-200.

Nelson D.L. y Cox M.M. 2000. Lehninger Principles of Biochemistry. Worth Publishers, Nueva York.

Nimmo H.G. 2003. How to tell the time: the regulation of phosphoenolpyruvate carboxylase in crassulacean acid metabolism (CAM) plants. Biochemical Society Transactions 31:728-730.

Nobel P.S. 1984. Productivity of Agave deserti: measurement by dry weight and monthly prediction using physiological responses to environmental parameters. Oecologia 64:1-7.

Nobel P.S. 1985. PAR, water and temperature limitations on the productivity of cultivated Agave fourcroydes (henequen). Journal of Applied Ecology 22:157-173.

Nobel P.S. 1986. Relation between monthly growth of Ferocactus acanthodes and an environmental productivity index. American Journal of Botany 73:541-547.

Nobel P.S. 1988. Environmental Biology of Agaves and Cacti. Cambridge University Press, Nueva York.

Nobel P.S. 1991a. Achievable productivities of certain CAM plants: basis for high values compared with $\mathrm{C}_{3}$ and $\mathrm{C}_{4}$ plants. New Phytologist 119:183-205.

Nobel P.S. 1991b. Environmental productivity indices and productivity for Opuntia ficus-indica under current and elevated atmospheric $\mathrm{CO}_{2}$ levels. Plant, Cell and Environment 14:637-646.

Nobel P.S. 1994. Remarkable Agaves and Cacti. Oxford University Press, Nueva York.

Nobel P.S. 2002. Cacti: Biology and Uses. University of
California Press, Los Angeles.

Nobel P.S. 2005. Physicochemical and Environmental Plant Physiology. Elsevier/Academic Press, San Diego.

Nobel P.S. y Bobich E.G. 2002. Environmental Biology. En: Nobel P. S. Ed. Cacti: Biology and Uses, pp. 57-74, University of California Press, Berkeley.

Nobel P.S. y De la Barrera E. 2002. High temperatures and net $\mathrm{CO}_{2}$ uptake, growth, and stem damage for the hemiepiphytic cactus Hylocereus undatus. Biotropica 34:225-231.

Nobel P.S. y De la Barrera E. 2004. $\mathrm{CO}_{2}$ uptake by the cultivated hemiepiphytic cactus, Hylocereus undatus. Annals of Applied Biology 144:1-8.

Nobel P.S., De la Barrera E., Beilman D.W., Doherty J.H. y Zutta B.R. 2002. Temperature limitations for cultivation of edible cacti in California. Madroño 49:228-236.

Nobel P.S. y Hartsock T.L. 1990. Diel patterns of $\mathrm{CO}_{2}$ uptake for epiphytic cacti differing in succulence. Physiologia Plantarum 78:628-634.

Nobel P.S. y Quero E. 1986. Environmental productivity indices for a Chihuahuan desert CAM plant, Agave lechuguilla. Ecology 67:1-11.

Nobel P.S. y Valenzuela A. 1987. Environmental responses and productivity of the CAM plant, Agave tequilana. Agricultural and Forest Meteorology 39:319-334.

Ogren W.L. 1984. Photorespiration: pathways, regulation, and modification. Annual Review of Plant Physiology and Molecular Biology 35:415-442.

Osmond C.B. 1978. Crassulacean acid metabolism: a curiosity in context. Annual Review of Plant Physiology 29:379-414.

Osmond C.B., Adams III W.W. y Smith S.D. 1994. Crassulacean acid metabolism. En: Pearcy R.W., Ehleringer J., Mooney H.A. y Rundel P.W. Eds. Plant Physiological Ecology. Field Methods and Instrumentation, pp. 255-280, Ch apman y Hall, Londres.

Pierce S., Winter K. y Griffiths H. 2002. Carbon isotope ratio and the extent of daily CAM use by Bromeliaceae. New Phytologist 156: $75-83$.

Pimienta-Barrios E., Robles-Murguía C., Ruiz-Corral J.A., Nobel P.S. y García-Galindo J. 1999. Regiones Térmicas Óptimas y Marginales Para el Cultivo de Agave tequilana en el Estado de Jalisco. Universidad de Guadalajara, Guadalajara.

Pittendrigh C.S. 1948. The bromeliad-Anopheles-malaria complex in Trinidad. I- The bromeliad flora. Evolution 2:58-89.

Raveh E., Gersani. M. y Nobel P.S. 1995. CO2 uptake and fluorescence responses for a shade-tolerant cactus Hylocereus undatus under current and doubled $\mathrm{CO}_{2}$ concentrations. Physiologia Plantarum 93:505-511.

Raven J.A. y Spicer R.A. 1996. The evolution of crassulacean acid metabolism. En: Winter K. y Smith J.A.C. Eds. Crassulacean Acid Metabolism. Biochemistry, Ecophysiology and Evolution, Springer, Nueva York.

Retallack G.J. 1997. Earliest Triassic origin of Isoetes and quillwort evolutionary radiation. Journal of Paleontology 71:500521.

Reyes-García C. 2005. Niche Differentiation in Contrasting Life-forms of Epiphytic Bromeliads from the Seasonally Dry Forest of Chamela, Mexico. Light and Water Use. Tesis doctoral, Department of Plant Sciences, University of Cambridge, Cambridge.

Reyes-García C. y Andrade J.L. 2007. Los isótopos estables del hidrógeno y oxígeno en los estudios ecofisiológicos de plantas. 
Boletín de la Sociedad Botánica de México 80:19-28.

Reyes-García C., Griffiths H., Rincón E. y Huante P. 2008. Niche differentiation in tank and atmospheric bromeliads of a seasonally dry forest. Biotropica. <doi:10.1111/j.1744-7429.2007.00359.x>

Reynolds J.F., Kemp P.R., Ogle K. y Fernandez R.J. 2004. Modifying the 'pulse-reserve' paradigm for deserts of North America: precipitation pulses, soil water, and plant responses. Oecologia 141:194-210.

Sage R.F. 2002. Are crassulacean acid metabolism and $\mathrm{C}_{4}$ photosynthesis incompatible? Functional Plant Biology 29:775785.

Santiago L.S., Silvera K., Andrade J.L. y Dawson T.E. 2005. El uso de isótopos estables en biología tropical. Interciencia 30:536-542.

Sayed O.H. 1998. Phenomorphology and ecophysiology of desert succulents in eastern Arabia. Journal of Arid Environments 40:177-189.

Sher A.A., Goldberg D.E. y Novoplansky A. 2004. The effect of mean and variance in resource supply on survival of annuals from Mediterranean and desert environments. Oecologia 141:353-362.

Schmidt G., Stuntz S. y Zotz G. 2001. Plant size—an ignored parameter in epiphyte ecophysiology? Plant Ecology 153:65-72.

Schwinning S. y Sala O.E. 2004. Hierarchy of responses to resource pulses in arid and semi-arid ecosystems. Oecologia 141:211-220.

Schwinning S., Sala O.E., Loik M.E. y Ehleringer J.R. 2004. Thresholds, memory, and seasonality: understanding pulse dynamics in arid/semi-arid ecosystems. Oecologia 141:191193.

Schwinning S., Starr B.I. y Ehleringer J.R. 2003. Dominant cold desert plants do not partition warm season precipitation by event size. Oecologia 136:252-260.

Silvera K., Santiago L.S. y Winter K. 2005. Distribution of crassulacean acid metabolism in orchids of Panama: evidence of selection for weak and strong modes. Functional Plant Biology 32:397-407.

Smith J.A.C. y Winter K. 1996. Taxonomic distribution of crassulacean acid metabolism. En: Winter K. y Smith J.A.C. Eds. Crassulacean Acid Metabolism. Biochemistry, Ecophysiology and Evolution, pp. 427-436, Springer, Berlín.

Smith J.A.C., Griffiths H., Lüttge, U., Crooks C.E., Griffiths N.M. y Stimmel K.-H. 1986. Comparative ecophysiology of CAM and $\mathrm{C}_{3}$ bromeliads. IV. Plant water relations. Plant, Cell and Environment 9:395-410.

Squeo F.A. y Ehleringer J. 2004. Isótopos estables: una herramienta común para la ecofisiología vegetal y animal. En: Cabrera H.M. Ed. Fisiología Ecológica en Plantas. Mecanismos y Respuestas a Estrés en los Ecosistemas, pp. 5980, Ediciones Universitarias de Valparaíso, Valparaíso.

Streb P., Josse E.M., Gallouet E., Baptist F., Kuntz M. y Cornic G. 2005. Evidence for alternative electron sinks to photosynthetic carbon assimilation in the high mountain plant species
Ranunculus glacialis. Plant, Cell and Environment 28:11231135.

Taiz L.y Zeiger E. 2002. Plant Physiology. Sinauer Associates, Inc., Publishers, Sunderland, Massaschusetts.

Tamis W.L.M., Van't Zelfde M, Van Der Meijden R. y Udo De Haes H.A. 2005. Changes in vascular plant biodiversity in the Netherlands in the twentieth century explained by their climatic and other environmental characteristics. Climate Change 72:37-56.

Ting I.P. y Burk J.H. 1983. Aspects of carbon metabolism in Welwitschia. Plant Science Letters 32:279-285.

Tolbert N.E. 1997. The C-2 oxidative photosynthetic carbon cycle. Annual Review of Plant Physiology and Molecular Biology 48:1-25.

Villers-Ruiz L. y Trejo-Vázquez I. 1997. Assessment of the vulnerability of forest ecosystems to climate change in Mexico. Climate Research 9:87-93.

von Willert D.J., Armbruster N., Drees T. y Zaborowski M. 2005. Welwitschia mirabilis: CAM or not CAM, what is the answer? Functional Plant Biology 32:389-395.

Winter K. y Holtum J.A.M. 2002. How closely do the ${ }^{13} \mathrm{C}$ values of crassulacean acid metabolism plants reflect the proportion of $\mathrm{CO}_{2}$ fixed during day and night? Plant Physiology 129:18431851 .

Winter K. y Smith J.A.C. 1996. An introduction to crassulacean acid metabolism: biochemical principles and biological diversity. En: Winter K. y Smith J.A.C. Eds. Crassulacean Acid Metabolism. Biochemistry, Ecophysiology and Evolution, pp. 1-13, Springer, Berlín.

Winter K. y Ziegler H. 1992. Induction of Crassulacean acid metabolism in Mesembryanthemum crystallinum increases reproductive success under conditions of drought and salinity stress. Oecologia 92:475-479.

Winter K., Wallace B.J., Stocker G.C. y Roksandic Z. 1983. Crassulacean acid metabolism in Australian vascular epiphytes and some related species. Oecologia 57:129-141.

Zotz G. 2002. Categories and CAM- blurring divisions, increasing understanding? New Phytologist 156:4-8.

Zotz G. 2004. How prevalent is crassulacean acid metabolism among vascular epiphytes? Oecologia 138:184-192.

Zotz G. y Andrade J.L. 1998. Water relations of two co-occurring epiphytic bromeliads. Journal of Plant Physiology 152:545554.

Zotz G. y Andrade J.L. 2002. La ecología y la fisiología de las epifitas y las hemiepifitas. En: Guariguata M.R. y Kattan G.H. Eds. Ecología y Conservación de Bosques Neotropicales, pp. 271-296, Libro Universitario Regional, Cartago, Costa Rica.

Zotz G. y Hietz P. 2001. The physiological ecology of vascular epiphytes: current knowledge, open questions. Journal of Experimental Botany 52:2067-2078.

Zotz G. y Winter K. 1994. Annual carbon balance and nitrogenuse efficiency in tropical $\mathrm{C}_{3}$ and CAM epiphytes. New Phytologist 126:481-492. 